\title{
A Promoção da Saúde a partir das situações de trabalho: considerações referenciadas em uma experiência com trabalhadores de escolas públicas
}

Edil Ferreira da Silva ${ }^{1}$

Jussara Brito²

Mary Yale Neves ${ }^{3}$

Milton Athayde 4

SILVA, E.F. et al. Health promotion from work situations: points relating to an experience among public school workers. Interface - Comunic., Saude, Educ., v.13, n.30, p.107-19, jul./set. 2009.

The objective of this paper was to present and discuss what we are calling "health promotion from work situations". For this, an experience developed in the state of Rio de Janeiro and in the municipality of João Pessoa, Paraíba, was used: the "Health, Gender and Work Training Program for Public Schools". The start and end points for this experiment were tangible work situations. From an ergological perspective, this experiment involved synergic dialogue between the "poles" of experience and concepts, mediated by the ethical-epistemological pole, through forming expanded research communities. Performing the experiment gave rise (and has been giving rise) to the production of a variety of health promotion events, encompassing tangible modifications to the organization and work environment, changes in the ways to fight for healthcare and even modifications in the way that work and life are regarded.

Keywords: Health promotion. Work. Public school. Workers' health. Ergology.
O objetivo deste artigo é apresentar e discutir o que está sendo por nós denominado Promoção da Saúde a partir das Situações de Trabalho (PSST). Para isto faz-se uso de uma experiência desenvolvida no estado do Rio de Janeiro e no município de João Pessoa/ PB: o Programa de Formação em Saúde, Gênero e Trabalho nas Escolas Públicas. Tal experimentação teve, como ponto de partida e chegada, as situações concretas de trabalho, e envolveu, numa perspectiva ergológica, o diálogo sinérgico entre os polos da experiência e dos conceitos, mediado pelo polo ético-epistêmico, pela constituição de Comunidades Ampliadas de Pesquisa (CAP). Sua realização propiciou (e vem propiciando) a produção de vários eventos promotores de saúde, englobando modificações concretas na organização e no ambiente de trabalho, mudanças nas formas de luta pela saúde e, mesmo, transformações no modo de olhar o trabalho e a vida.

Palavras-chave: Promoção da saúde. Trabalho. Escola pública. Saúde do trabalhador. Ergologia.
${ }^{1}$ Departamento de Psicologia, Universidade Estadual da Paraíba. Rua Dr. Ephigênio Barbosa da Silva, 450, bloco

A, apto. 203. Jardim Cidade Universitária, João Pessoa, PB, Brasil. 58.052-310

edilsilva@uol.com.br ${ }^{2}$ Centro de Estudos da

Saúde do Trabalhador e Ecologia Humana, Escola Nacional de Saúde Pública, Fundação Oswaldo Cruz, ${ }^{3}$ Departamento de Psicologia, Universidade Federal da Paraíba. ${ }^{4}$ Programa de PósGraduação em Psicologia Social, Instituto de Psicologia, Universidade Estadual do Rio de Janeiro. 


\section{Introdução}

Neste artigo - que se insere na interface do campo da Promoção da Saúde com o da Saúde do Trabalhador - visamos apresentar e discutir o que estamos denominando "Promoção da Saúde a partir das Situações de Trabalho" (PSST). Utilizamos, como referência, um dispositivo de formação-pesquisa-intervenção em rede que vimos desenvolvendo, desde 2000, no sudeste (estado do Rio de Janeiro) e no nordeste (município de João Pessoa/PB): um Programa de Formação articulado a um Programa de Pesquisas, voltados para a análise e a ação transformadora. Essa experimentação de longa duração - denominada "Programa de Formação em Saúde, Gênero e Trabalho nas Escolas Públicas" (Brito, Athayde, Neves, 2003a, 2003b) - buscou, simultaneamente, melhor compreender e transformar o trabalho em suas relações com a saúde, por meio de uma proposta de formação do conjunto de trabalhadores de escola interessados na experimentação (professores, diretores, merendeiras e auxiliares de serviço, vigilantes etc.) para coatuar neste empreendimento.

Nossos pontos de partida e chegada foram as situações concretas de trabalho, o que envolveu, numa perspectiva ergológica (Schwartz, Durrive, 2007; Schwartz, 2000a), o debate sinérgico entre os polos ${ }^{5}$ da experiência (da prática operacional) e dos conceitos (das disciplinas acadêmico-científicas), mediado pelo polo ético-epistêmico, gerando acontecimentos e fluxos produtores de saúde. A proposta foi desenvolvida após uma avaliação de que, para o tratamento da problemática em foco, seria necessário que se conjugassem pesquisas sistemáticas, debates contínuos entre pesquisadores e trabalhadores de escola e ações cotidianas nos locais de trabalho. Cabe ainda acrescentar que esta iniciativa teve como demanda inicial o pedido de socorro que emergiu do movimento dos trabalhadores de escola do Rio de Janeiro, por meio do Sindicato Estadual dos Profissionais de Educação (SEPE-RJ). Em seus fóruns, buscavam entender o que estava em curso com a saúde deste coletivo nas escolas, pois os próprios trabalhadores percebiam o crescente número de colegas afastados ou em vias de adoecimento. Tal proposta de experimentação foi, em seguida, negociada com o Sindicato dos Trabalhadores em Educação do Município de João Pessoa (SINTEM). Tivemos, portanto, a parceria com os dois sindicatos representantes dos diferentes segmentos profissionais do trabalho em escola, em ambas as regiões.

A implementação desta modalidade de formação-pesquisa-intervenção foi antecedida por um conjunto de investigações (Athayde et al., 2001; Souza, 2000; Nunes, 2000; Neves, 1999; Brito, Athayde, Neves, 1998). Não obstante o patrimônio presente na comunidade científica sobre as relações entre condições de vida, trabalho e saúde dos trabalhadores de escola, entendemos que nos faltavam materiais de outra qualidade, em que a trama que se tecia para chegar a transformar as condições de trabalho em curso exigia outro tipo de dispositivo.

A linhagem da psicologia ergonômica e da ergonomia da atividade francofônica (para quem a exigência de respeito à saúde sempre foi um determinante destacado), desde os anos 50 (Ombredane, Faverge, 1955), já sinalizava a importância das relações entre análise do trabalho e formação. Nos anos 70, a questão da formação já apresentava, neste campo, um perfil consistente, tendo destaque figuras como Catherine Teiger e Antoine Laville. Esta modalidade de "formação pela e para a ação" (Lacomblez, 1995; Teiger, Laville,1991) propõe que a aprendizagem da análise do trabalho desenvolva, simultaneamente, a tomada de consciência e confiança no engajamento da ação. Por um lado, trata-se de reconstituir - rigorosamente e com detalhes, incorporando neste processo os protagonistas da atividade (especialmente via verbalização e formas
${ }^{5} \mathrm{Na}$ perspectiva ergológica aqui operada, o vocábulo polo está associado à ideia de saberes que se atraem sinergicamente, de forma heurística. Em verdade, fazemos aqui alusão ao dispositivo de três polos da ergologia, que viabiliza uma metodologia na busca da contribuição das disciplinas científicas e da experiência dos "interlocutores da atividade". O primeiro é o polo das disciplinas científicas, cujo objeto de estudo é o trabalho. Diversas disciplinas contribuem na compreensão da atividade. É “o pólo dos conceitos que comporta materiais para o conhecimento". O segundo é o polo das forças de convocação e validação que estão na origem das demandas e na transformação das situações em cada contexto histórico. Pode fazer parte deste polo qualquer ator social. O terceiro é o polo das exigências éticas e epistemológicas no campo da produção de conhecimento. É o lugar de discussão e entendimento, onde são definidos "os objetivos e os interesses" de um trabalho conjunto, que pressupõe um respeito mútuo entre estes dois registros de conhecimento (Schwartz, Durrive, 2007; Schwartz, 2000a, 2000b). 
de autoconfrontação) - como se realizam, de fato, as tarefas, para além do prescrito. Por outro lado, a formação se torna meio de ação ergonômica transformadora, pois procede de uma mudança de ponto de vista, de uma abertura perceptual e conceitual. Assim, a consistência da mudança encontra-se tanto na fecundidade das análises efetuadas, quanto na compreensão e confiança dos trabalhadores pertinentes e responsáveis pelo empreendimento. Não se trata, é claro, de uma fórmula de conscientização pedagogizante, mas de mútua aprendizagem (envolvendo cultura/incultura recíproca, assim como o desconforto intelectual), inclusive por parte dos profissionais da ciência envolvidos.

Neste sentido, o primeiro pressuposto era o de que o patrimônio de conhecimento já produzido precisaria ser socializado e colocado em debate de modo sistemático e com propósitos determinados (o principal deles: compreender-transformar positivamente o trabalho). Por outro lado, percebia-se a necessidade de uma atualização permanente das informações relativas às situações concretas de um número maior de escolas (e regiões do estado, no caso do Rio de Janeiro), para que fossem geradas propostas e teorizações generalizáveis, voltadas à promoção da saúde.

A elaboração de um projeto, no início de 2000, aprovado e financiado pelo Fundo de Igualdade de Gênero da Agência Canadense para o Desenvolvimento Internacional (FIG/CIDA), permitiu a sistematização de um método e sua experimentação, inicialmente no estado do Rio de Janeiro e no município de João Pessoa/PB, desenvolvendo-se também, posteriormente, no Espírito Santo, além de em outros lugares de que não temos acompanhamento. Um método que poderíamos definir como de Promoção da Saúde a partir das Situações de Trabalho (PSST), e que foi sistematizado em duas publicações para uso no referido Programa. A primeira é relativa à preparação metodológica: Caderno de Método e Procedimentos (Brito, Athayde, Neves, 2003a). A outra reúne um conjunto de textos propostos para discussão, o Caderno de Textos (Brito, Athayde, Neves, 2003b). Ambos estão baseados em estudos que antecederam a realização do próprio Programa, sendo atualizados e reelaborados a partir da aquisição de maior conhecimento sobre uma determinada perspectiva de compreensão da atividade humana: a perspectiva ergológica (Schwartz, Durrive, 2007; Brito, Athayde, 2003; Schwartz, 2000a), que desde a década de 1980 vem explorando heuristicamente as descobertas e experimentações da linhagem da ergonomia da atividade, seja nos países francofônicos (Daniellou et al., 2004; Guérin et al., 2001; Wisner, 1994), seja na Itália (com Oddone, Re, Brianti, 1981, e o Movimento Operário Italiano de luta pela saúde).

Neste artigo nos empenhamos especialmente em mostrar que tal tipo de experimentação pode se constituir em uma importante ferramenta de promoção da saúde, cuja especificidade é dar pertinência estratégica ao trabalho concreto, às situações em que ele se desenvolve. Assim, inicialmente, problematizaremos a proposta de Promoção da Saúde nos Locais de Trabalho (PSLT), por meio do suporte fornecido pela literatura que segue essa tradição. Este caminho permitirá que formulemos a proposição de Promoção da Saúde a partir das Situações de Trabalho (PSST), um modo particular de realizar ações neste campo. Após a apresentação desta ideia, nos dedicaremos à caracterização do método empregado no desenvolvimento do Programa de Formação em Saúde, Gênero e Trabalho nas Escolas Públicas. Na parte final do artigo, elencaremos alguns resultados desta experimentação, discutindo-os à luz da Promoção da Saúde a partir das Situações de Trabalho.

\section{Da "Promoção da Saúde nos Locais de Trabalho" (PSLT) à "Promoção da Saúde a partir das Situações de Trabalho" (PSST)}

A proposta de PSLT foi elaborada pela Organização Panamericana de Saúde - OPAS, e anunciada em março de 2000. Tal documento, intitulado "Estratégia de Promoção da Saúde nos Locais de Trabalho da América Latina e Caribe", é dirigido às autoridades governamentais, lideranças empresariais, sindicatos, associações profissionais, organizações não-governamentais e à comunidade em geral, explicitando o objetivo da proposta:

Contribuir para a melhoria do ambiente físico e psicossocial, o estado de saúde, a capacidade para ter valores e estilos de vida e trabalho mais saudáveis e o bem-estar geral dos trabalhadores, com o fim de avançar em direção ao desenvolvimento sustentável com equidade e justiça social (OPAS, 2000, p.9). 
Com esta proposição, a OPAS pretendia sensibilizar todos os envolvidos de maneira direta e indireta acerca da importância da questão. Buscava ainda fortalecer a capacidade técnica e institucional dos países para formular, executar e avaliar políticas e programas eficazes que tornassem os ambientes de trabalho mais saudáveis. Ou seja, a PSLT envolveria

uma série de políticas e atividades nos locais de trabalho, desenhadas para ajudar aos empregadores e trabalhadores em todos os níveis, a aumentar o controle sobre sua saúde e a melhorá-la, favorecendo a produtividade e a competitividade das empresas e contribuindo ao desenvolvimento econômico e social dos países. (OPAS, 2000, p.4)

Não temos dúvida de que essa iniciativa é muito importante e, por esse motivo, deve ser problematizada e desenvolvida. A nosso ver, um dos problemas da proposta é seu caráter ainda genérico - o que talvez não pudesse ser muito diferente, uma vez que se trata de uma declaração de intenção. Mas, na medida em que busca contribuir com "a capacidade para ter valores e estilos de vida e trabalho mais saudáveis", entendemos que identifica a saúde a um capital a ser mobilizado (Surateau, 2000), independente do contexto social, com suas contradições e especificidades. A definição de local de trabalho saudável também não nos parece algo simples. Em primeiro lugar, porque os processos produtivos não são estáveis, implicando permanentes mudanças do ambiente de trabalho. Em segundo lugar, porque certamente há concepções diferenciadas de ambiente saudável entre os atores pertinentes, ou seja, devemos considerar a existência de um debate de valores sobre esta questão: quem define que o ambiente é saudável, com que critérios, em que conjuntura? (Schwartz, 2007, 2000a). Parece-nos fundamental, ainda, considerar que há situações que privam os indivíduos de sua capacidade de criticar mais incisivamente os meios de vida com os quais interagem, como indica Surateau (2000) ao discutir a obra de Canguilhem. A nosso ver, propostas formuladas em uma visão de exterioridade em relação às situações concretas, objetivando sua aplicação no local de trabalho, sempre apresentarão um descompasso em relação à experiência compartilhada por homens e mulheres em determinada situação concreta - experiência que envolve inclusive saberes ligados à própria luta pela saúde. Logo, iniciativas como essa serão melhor sucedidas se autorizadas (no sentido clínico) pelos trabalhadores.

Neste sentido, uma questão importante diz respeito à defasagem sempre existente entre o trabalho prescrito e o trabalho real, evidenciada pela ergonomia da atividade - campo do conhecimento que, desde o pós-guerra, já apontava a necessidade de adaptar o trabalho às pessoas, invertendo e revolucionando a lógica taylorista predominante de adequar os homens ao trabalho (Daniellou et al., 2004; Guérin et al., 2001). O trabalhar envolve uma dimensão sempre enigmática e simbólica, em que a atividade possui um volume de negociações - cognitivas, afetivas e sociais - que excedem o que é diretamente observável e mensurável (Dejours, 2004; Schwartz, 2000a). Deste modo, na adoção de ações dirigidas à promoção da saúde vinculadas aos locais de trabalho, torna-se imprescindível incorporar e desenvolver a experiência e o pensamento sobre o trabalho dos protagonistas da atividade situada. Ou seja, para se avaliar se um ambiente é saudável, revela-se indispensável levar em conta os atores (individuais e coletivos) da situação e o modo como estruturam sua atividade, sob pena de a intervenção em direção às mudanças pretendidas não ter sucesso.

O esforço aqui é por entender o trabalho como uma relação social que não é somente heterodeterminada, mas produto de homens e mulheres concretos que mobilizam a si e às redes sociais pertinentes para desenvolver sua atividade. Trabalhar pode configurar-se como um desafio, enfrentamento, e, nesse processo, contribuir para a conquista de sentido e de uma economia psicossomática adequada, tornando-se uma aventura humana na direção da sua "realização" (sempre inacabada) enquanto ser vivo individual e coletivo (Dejours, 2004). Assim, o trabalho, para que se o compreenda-transforme, tem de ser analisado em sua complexidade, como um campo de contradições e determinações múltiplas, de (in)culturas, de valores e de relações sociais de produção com trajetórias diversas. Em síntese, um campo mediado pela história singular e social desses agentes.

Dejours, partindo das descobertas da ergonomia da atividade, busca ir adiante e assim define trabalho: "é a atividade coordenada desenvolvida por homens e mulheres para enfrentar aquilo que, 
em uma tarefa utilitária, não pode ser obtido pela execução estrita da organização prescrita" (Dejours, 1997, p.43). Explorando o conceito de atividade subjetivante, ele cria novos conceitos para dar conta da complexa produção psíquica e cultural que procede da experiência da prática - uma inteligência astuciosa, corporal, que está à frente da consciência e que exige passar por julgamento de outrem, transformando-se em sabedoria da prática (Dejours, 2004). Verifica-se então o que aí se denomina psicodinâmica do reconhecimento, decisiva para o fortalecimento da identidade, ossatura da saúde, em termos psicossomáticos. Uma parte do real resiste - o real do trabalho - irredutível ao domínio intelectual vigente, desafiando-nos individual e coletivamente no curso do trabalho, mobilizando corpo e alma.

Clot $(2008,2006)$, com base em referenciais diferentes de Dejours, vem também enriquecendo o conceito de atividade, desdobrando-o em: atividade realizada e real da atividade. Em sua leitura, a atividade realizada é aquilo que se faz, no sentido do que se apresenta no plano comportamental (dos modos operatórios diretamente observáveis). Na verdade, uma parte ínfima do que se pode vir a fazer (trata-se apenas de uma atualização de uma das atividades possíveis na execução da tarefa). Com o conceito de real da atividade, Clot pretende também envolver aquilo que não se faz, o que se procura fazer sem lograr êxito. Explorando a concepção vigotskiana, ele assinala que as atividades contrariadas, suspensas ou impedidas devem também ser admitidas na análise, pois não estão ausentes da vida do trabalho, ao contrário, emergem aí com destaque. Trata-se de uma linhagem já explorada também por Oddone com o Modelo Operário Italiano de luta pela saúde - MOI (Oddone, Re, Brianti, 1981) -, críticos de uma visão pejorativa (predominante) do homem no trabalho, mesmo entre os críticos do capitalismo, que o veem como inteiramente subordinado à exploração-dominação. Com esse conjunto de argumentos, operamos um deslocamento na direção de uma proposta de promoção da saúde a partir das situações de trabalho, cujas bases principais são:

- O entendimento de saúde por meio de um conceito positivo, que enfatiza os recursos sociais e pessoais, bem como as capacidades físicas; algo multidimensional que vai muito além da ausência de doença, ou limitado a temas de estilo de vida e comportamento.

\section{- O caráter situado do trabalho (a atividade situada), com suas limitações e possibilidades.}

- O desenvolvimento da experiência (Clot, 2006) e a busca da expansão do poder de agir dos trabalhadores (Clot, 2008) tendo em vista condições de vida e trabalho mais adequadas à sua saúde.

A noção de situação está diretamente relacionada com a concepção de centralidade do trabalho. Seja como abordada por Freire (1983), que envolve tempo-espaço e ação, seja pela ergonomia da atividade (Rabardel et al., 2007), neste caso a ela referindo-se como contexto concreto (físico, técnico e histórico) em que os homens realizam uma produção material ou imaterial, em condições de trabalho e segurança dados, podendo também ser entendida como um sistema constituído de numerosos elementos - dispositivo técnico e material, organização do trabalho, trabalhadores e suas competências.

A valorização da atividade de trabalho (o ponto de vista da atividade) envolve a dialética sempre presente entre as diversas formas de atividade, enfatizando sua potência transversal em relação às outras. Em consequência, tudo que for pensado em termos locais deve também ser pensado em termos globais: novas convocações/validações dos trabalhadores; propostas de políticas públicas; mudanças na legislação; articulações intersetoriais, com os clientes/usuários do serviço (diferentes setores da sociedade) etc. (Schwartz, Durrive, 2007).

A concepção de centralidade do trabalho, calcada no Modelo Operário Italiano de luta pela saúde (MOI), sob a influência de Gramsci (Vicenti, 1999; Athayde, 1988), indica que é somente no interior de cada estabelecimento que se pode exercer, de modo contínuo, eficiente, uma ação de real defesa do trabalho e da saúde do homem (Oddone et al., 1986). Portanto, remete também ao desenvolvimento do sentido do trabalho por meio do reconhecimento da atuação concreta dos 
trabalhadores. Trabalhar permite, ao fazer uso de si, por si e por outrem (Schwartz, 2007, 2000a), buscar um ciclo virtuoso, uma heurística psicodinâmica do reconhecimento, em que a visibilidade do seu fazer, passando pelo julgamento deste fazer - por intermédio do reconhecimento da hierarquia (diretores de escola, por exemplo), de seus pares (colegas de trabalho) ou da clientela (dos alunos e familiares) - conduz à retribuição de sua contribuição ao trabalho, por meio do reconhecimento de seu esforço pela hierarquia (diretores de escola, por exemplo), de seus pares (colegas de trabalho) ou da clientela (dos alunos). Como afirma Dejours "o reconhecimento é a forma específica da retribuição moral-simbólica dada ao ego, como compensação por sua contribuição à eficácia da organização do trabalho, isto é, pelo engajamento de sua subjetividade e inteligência" (Dejours, 1997, p.55).

A PSST deve considerar a capacidade de criação de novas normas de vida (Canguilhem, 1995) e valorizar as normas efetivamente geradas na atividade, muitas vezes não traduzidas em palavras, reconhecendo a experiência dos trabalhadores como fundamental no processo de compreendertransformar-compreender. Aqui, experiência não se limita ao vivido, mas ao seu modo de desenvolvimento. A dramática cotidiana dos trabalhadores é mais que um conjunto de fatos; é uma trama tecida - horizontal e verticalmente, transversalmente - que, na maioria das vezes, não é plenamente consciente para eles, além de escapar à observação dos especialistas.

É preciso que esta experiência dos trabalhadores seja mobilizada, já que a consideramos decisiva, incontornável fonte de conhecimento da relação trabalho-saúde. Não para esta experiência ser cristalizada, como um passado a ser recuperado intacto, mas para que, por meio de um dado tipo de mobilização, tal patrimônio de experiência propicie o desenvolvimento de outras experiências (Clot, 2004; Clot, Faïta, 2000). Para isto é necessário que se opere com um dispositivo que contribua para o diálogo sinérgico deste polo da experiência com o polo dos conceitos, das disciplinas científicas (Schwartz, Durrive, 2007; Schwartz, 2000b). Ou seja, a experiência dos trabalhadores tem de ser não só reconhecida em sua importância, mas tornar-se um meio para engendrar outras experiências, ela própria transformando-se. Explorando os materiais vigotskianos, pode-se dizer que, por um lado, um fenômeno só pode ser investigado em seu movimento (Vigotski, 1999a); por outro, que a consciência é a experiência vivida de experiências vividas (Vigotski, 1999b apud Clot, Faïta, 2000). Assim sendo, o patrimônio de experiência dos protagonistas da atividade de trabalho só pode ser apreendido de modo fértil quando muda de estatuto, no curso de sua própria transformação. É na medida em que o trabalhador se desloca de sua própria experiência de trabalho que ela se disponibiliza, se torna um meio de fazer outras experiências.

Esta sinergia entre a experiência dos trabalhadores e o conhecimento cientificamente elaborado tem um valor heurístico na medida em que pode resultar na produção de um novo conhecimento e, também, no desenvolvimento de outras experiências no trabalho, mais pertinentes às características singulares da nova situação. Além do mais, as experiências que lograram êxito devem ser traduzidas em indicações, técnicas e métodos veiculados inclusive na forma escrita. Deste modo, lembrando Dejours (1997), estamos no plano do reconhecimento da contribuição do trabalhador à organização real do trabalho.

Cabe ressaltar que a participação do polo das ciências neste processo é fundamental, por possibilitar que os conceitos espontâneos (no vocabulário vigotskiano) possam fluir em uma dinâmica ascendente-descendente com os conceitos científicos, serem debatidos e sistematizados, gerando novos conhecimentos. Sua função não é apenas colocar a serviço do polo da experiência o conhecimento cientificamente estabelecido, mas estar aberto à convocação dos trabalhadores e procurar, por meio deste tipo de diálogo, mutuamente crítico, encontrar respostas, inclusive a partir de um retrabalho no interior das disciplinas científicas. A nosso ver, esta abordagem, herdeira de outras experimentações respeitadas no campo da Saúde do Trabalhador, procura ir adiante.

A metodologia utilizada no "Programa de Formação em Saúde, Gênero e Trabalho nas Escolas" está assentada nessas bases, conforme veremos em seguida.

\section{Programa de formação em saúde, gênero e trabalho nas escolas - características metodológicas}

No decorrer das pesquisas que vinham sendo realizadas (já referidas na Introdução), avaliamos que nos faltava um dispositivo que radicalizasse a incorporação daqueles que vivenciam a situação 
real de trabalho, com o fim de compreender-transformar o trabalho. Faltava-nos um dispositivo que colaborasse para a emergência dos saberes da prática, viabilizando o diálogo sinérgico com conceitos, métodos e resultados de pesquisas científicas, de modo que ambos os polos (do conceito e da experiência) pudessem se desenvolver. Ele foi desenhado de forma a viabilizar uma expansão (multiplicação) do número de trabalhadores "capacitados", com informações advindas dos polos da ciência e da própria experiência (neste caso retirando-o de sua individualização e naturalização), para uma ação mais fecunda na luta pela transformação das condições geradoras de nocividade e da afirmação dos potenciais de saúde. Seu desenho buscou, também, mobilizar as experiências dos participantes, considerando a transversalidade das relações sociais de gênero, isto é, sua presença/ influência em todos os espaços sociais (Kergoat, 2002, 1996, 1986; Hirata, 2002, 1993; Brito, 1996). Implicaria, assim, uma vigilância constante sobre as nocividades do local de trabalho e na construção de um Observatório sobre as relações saúde-trabalho.

A proposta de desenvolvimento deste Programa de Formação ocorreu no momento que acreditávamos ser o mais pertinente para darmos início ao que, neste processo, denominamos Comunidade Ampliada de Pesquisa (CAP), um espaço de confrontação-cooperação entre saberes científicos e práticos (Brito, Athayde, 2003; Brito, Athayde, Neves, 2003a).

Em termos metodológicos, este Programa foi organizado em ciclos, cada um deles com duas fases. O primeiro ciclo tem uma especificidade, pois se inicia com a formação dos primeiros multiplicadores, que não só participam do ciclo seguinte, como deveriam fazê-lo cada vez mais, assumindo as responsabilidades por tal processo. Os ciclos seguintes concernem à reprodução (não mecânica) ampliada da formação. Cada ciclo envolve duas fases, planejadas porque a proposta do Programa de Formação é possibilitar que a experiência - concreta, singular, de cada trabalhador, de cada coletivo, de cada escola - venha à tona para todos (produzindo-se nos planos linguageiro e do pensamento) e se desenvolva. Sim, pois é no diálogo e no debate coletivo que poderá ocorrer o desenvolvimento dessa experiência, ampliando a capacidade dos coletivos de trabalho de compreender-transformar.

\section{Fase 1 - curso, com carga horária prevista inicialmente de vinte horas, para a qual previmos o encadeamento dos seguintes momentos:}

a) primeiro, a exposição de "temas geradores" (Freire, 1989, 1967) por profissionais de pesquisa (nos ciclos seguintes incorporando os multiplicadores, trabalhadores que já participavam do Programa e já tinham uma certa compreensão da abordagem científica sobre o assunto específico), com o objetivo de informá-los sobre o que consideramos mais relevante no campo científico. Ao final das exposições, o debate não ocorre imediatamente em seguida, propomos que se aproveite a presença dos especialistas expositores apenas para esclarecimentos sobre os temas;

b) em seguida, a leitura em duplas (ou individualmente, ou em pequenos grupos) do Caderno de Textos, previamente elaborado com base em estudos anteriormente realizados, a propósito dos temas geradores apresentados;

c) em um terceiro momento, discussão em grupos menores sobre os temas tratados (já apresentados e lidos). Inspirados em uma "Pedagogia da Pergunta" (Freire, Faúndes, 1985), vaise produzindo um movimento dialógico, cujo efeito é o maior envolvimento, comprometimento (Freire, 1989) e desenvolvimento dos participantes (individual e coletivo). Neste trabalho em grupo, o papel da coordenação não é validar esta ou aquela compreensão, mas estritamente colaborar para o questionamento do tema, assim como das formulações inicialmente apresentadas pelo expositor e pelo texto.

d) ao final, reunidos todos os participantes, socialização do que foi discutido nos grupos menores, seguida por novo debate, sem a busca de síntese, visando-se com este encaminhamento - uma espécie de "fazer grupo como obra aberta" -, o desenvolvimento, o devir outro (Benevides de Barros, 2007). 
Para fechar esta fase, as três últimas sessões do curso são reservadas para a discussão e programação da continuidade do Programa de Formação - o que implica a definição de focos de atenção para os exercícios de estudo de campo (segunda fase). A proposta de focos de estudo se baseia na análise das discussões realizadas nos subgrupos e no grupo. Esta é apresentada aos participantes do curso, que passam a debatê-la e aprimorá-la. Definidos os focos, os participantes elegem coletivamente um dos focos para dar início aos "exercícios de estudo de campo" e, em subgrupos, discutem os elementos que o envolvem e suas interfaces. Em seguida, passam ao momento de definição das estratégias e procedimentos de estudo a serem utilizados no exercício.

\section{Fase 2 - alternâncias entre estudos de campo e debate na CAP:}

- momento 1: após o curso, retorno às escolas para exercícios de estudos de campo sobre os focos;

- momento 2: encontros sistemáticos do que denominamos Comunidade Ampliada de Pesquisa CAP (na qual circula uma comunidade dialógica, cf. França, 2007), após cada exercício, para discussão sobre a experiência, os achados e as possíveis mudanças a serem experimentadas e eventualmente reivindicadas para toda a rede de ensino.

Durante estas duas fases espera-se que possam ir se forjando as alianças com os trabalhadores das escolas, caminhando na direção de construção permanente do que Schwartz (2007b) denomina terceiro polo (em seu dispositivo dinâmico de três polos), de cunho ético-epistêmico, conforme já assinalado anteriormente, ganhando em grandeza a CAP. Esta, por seu lado, iria possibilitando o diálogo/confronto entre os polos das disciplinas científicas e da experiência da prática, abrindo novas linhas de investigação e intervenção, engendrando assim sua ampliação e consolidação como instrumento. Dessa forma, a CAP é um dispositivo metodológico (na perspectiva ergológica) que tem no seu interior uma técnica de encaminhamento do processo ensino/aprendizagem - o curso -, técnicas de investigação/ação, calcada nos exercícios de estudo de campo e técnicas de discussão, análise e validação dos materiais produzidos (sempre registrados e transcritos), baseadas no diálogoconfronto entre experiência e conceito - os Encontros sobre o Trabalho.

Entre os anos de 2000 e 2007, 186 trabalhadores de diversas escolas (141 do estado do Rio de Janeiro e 45 do município de João Pessoa) participaram diretamente dos ciclos de formação, distribuindo-se entre 156 mulheres e trinta homens. Se considerarmos que as atividades de exercício de pesquisa de campo envolveram a construção de relações sociais nas escolas - o que configura uma sensibilização dos trabalhadores não diretamente envolvidos no Programa - aumenta muito o número de pessoas que já vêm se engajando e/ou com potencial para o monitoramento das condições de trabalho (em um Observatório). Este conjunto de trabalhadores foi composto, sobretudo, por: professores, merendeiras e serventes (auxiliares de serviço), havendo um número reduzido de diretores, técnicos em educação, inspetores de alunos, vigilantes, agentes administrativos e outros profissionais de nível superior (psicóloga e assistente social).

\section{Resultados e discussão}

Em função do escopo e objetivo deste artigo - apresentar para discussão as possibilidades de promoção da saúde a partir das situações de trabalho por meio de um dispositivo de formaçãopesquisa-intervenção em rede com as características anunciadas - destacaremos aqui somente alguns resultados concernentes ao desenvolvimento da experiência dos trabalhadores. Não trataremos aqui das análises efetuadas sobre os movimentos discursivos, fazendo uso de método dialógico inspirado em Bakhtin (2003), Faïta (2005) e França (2007), efetuadas após transcrição dos registros dos debates em áudio e que se constituem em material importante para compreensão dos problemas.

Em primeiro lugar, podemos afirmar que, na trama da CAP, foi se tecendo um tipo de sociabilidade que reuniu horizontalmente os diversos tipos de profissionais de escola. Esta forma de parceria colaborou para a emergência sistemática de uma diversidade de olhares, de concepções de homens 
e mulheres acerca dos problemas do mundo do trabalho escolar, das questões de saúde e gênero, possibilitando sua objetivação e desnaturalização (Costa, 2004; Silva, 2003).

Os debates sobre saúde (enquanto valor e conceito) - em sua relação com o trabalho empreendidos no processo de formação dos trabalhadores participantes do Programa, parecem-nos ter permitido (re)pensar o trabalho, as atividades e suas implicações sobre o processo saúde/doença, abrindo-se um leque de possibilidades para a transformação da vida no trabalho em prol da saúde. Pudemos observar que uma das mudanças mais importantes ocorridas no percurso da formação esteve relacionada à superação da naturalização do adoecimento, na medida em que os trabalhadores sinalizaram que a participação no Programa de Formação veio despertá-los para as profundas relações que o trabalho tem efetivamente com a sua saúde.

Além das mudanças no plano pessoal, percebemos o surgimento de pequenos focos não só de reação ao processo de trabalho instituído nas escolas, como também de proposição de mudanças e a criação de estratégias (individuais e coletivas) em prol da saúde e da afirmação da vida. Mas, como o quadro de participantes tinha como marca a diversidade de segmentos profissionais, percebemos formas diferenciadas de colocar em prática encaminhamentos que favorecessem a saúde nas situações e ambientes de trabalho. O nível de envolvimento e compreensão do processo de formação não se efetivou de forma homogênea (nem era essa a expectativa). Durante este processo, algumas mudanças, de naturezas diversas - englobando modificações concretas na organização e no ambiente de trabalho, mudanças nas formas de luta pela saúde e, mesmo, transformações no modo de olhar o trabalho e a vida - já aconteceram em várias escolas do estado do Rio de Janeiro e do município de João Pessoa. Podemos dar alguns exemplos.

No que tange à organização e condições de trabalho, um dos grupos conseguiu implementar a divisão de horários do recreio por faixa etária dos alunos, após a avaliação dos benefícios que isso traria naquele contexto específico, considerando a atividade ali desenvolvida, com suas singularidades. O processo de trabalho das merendeiras de uma escola desprovida de refeitório foi parcialmente modificado, após perceberem, confrontadas com fotos, que seria menos desgastante se os próprios alunos buscassem suas refeições na cozinha, localizada no piso inferior. Houve também relatos de mudanças na própria estrutura de alguns prédios visando espaços mais adequados, assim como adaptação de equipamentos tendo em vista a segurança e um maior conforto. Foi o caso da colocação de rodinhas no fogão para evitar que as merendeiras de uma escola continuassem a levantar panelas pesadas. Assim como a diminuição das pernas dos fogões de outras escolas, para tornar sua altura mais adequada e menos prejudicial à saúde dessas trabalhadoras.

No que concerne ao debate nos sindicatos, podemos dizer que houve um aumento significativo de exposições sobre a relação saúde-trabalho nos eventos dos trabalhadores realizados tanto no Rio de Janeiro, quanto em João Pessoa. Do mesmo modo, no decorrer do Programa, o movimento sindical decidiu criar o Coletivo de Gênero, Saúde e Etnia, como parte da estrutura do Sindicato dos Trabalhadores da Educação do Município de João Pessoa - SINTEM. Nesse período vimos também a criação da Secretaria de Saúde no Sindicato Estadual dos Profissionais da Educação - SEPE/RJ. Consequentemente, houve uma ampliação das formas de luta pela saúde. O SEPE/RJ realizou uma campanha de valorização profissional, denunciando a falta de profissionais e suas doenças mais comuns em painéis colocados nos out-bus e nas escolas. A campanha foi estendida também para os locais de trabalho, onde foram distribuídos adesivos em todas as escolas com os seguintes dizeres: "se não é minha função não faço" (dirigida aos funcionários administrativos) e "em salas super lotadas não dou aula" (dirigida aos professores).

O Programa teve ainda efeitos sobre a adoção de políticas públicas. Em João Pessoa, uma decisão importante da Secretaria de Educação foi a de substituir os quadros-negros por quadros brancos nas escolas, eliminando a nocividade do pó de giz, entre outros ganhos. Outra medida importante foi pertinente à licença por motivo de doença. Até então, os trabalhadores, ao se licenciarem por motivo de adoecimento, perdiam os $25 \%$ de adicional de produtividade a que tinham direito. $\mathrm{O}$ governo municipal passou a conceder a licença, para determinados tipos de doenças (asma, problemas neurológicos, cardiológicos, cânceres etc.), sem perda da gratificação. 
Acompanhando os trabalhadores nessa travessia, fomos percebendo que as mudanças éticoestéticas aconteciam também na aparência física, na forma de se expressar, de cuidar da sua saúde e da saúde de sua família (Costa, 2004). Além disso, ao se introduzirem as relações sociais de gênero como um dos eixos transversais, o Programa de Formação tinha como objetivo buscar construir, junto com os trabalhadores de escola, processos de conhecimento não mais "sexualmente cegos", mas produzir novas formas de pensar, sentir e agir em relação às questões de gênero, saúde e trabalho na escola.

Pudemos registrar resultados dessa ordem em todos os ciclos e fases do Programa, o que configura o caráter de pesquisa-intervenção desta experimentação. Ao longo dos exercícios de estudo de campo, os trabalhadores foram desenvolvendo sua capacidade de visibilizar certas situações do trabalho na escola que costumam escapar ao olhar do profissional de pesquisa, sempre estranho e estrangeiro ao trabalho em análise. Com efeito, para se aprofundar o conhecimento acerca do real do trabalho e do real da atividade, deve-se enfatizar a contribuição indispensável dos protagonistas da atividade. À medida que os trabalhadores de escola foram se apropriando das informações sobre seu trabalho e suas implicações em termos de saúde/doença, foram, neste processo, provocando alterações em sua própria atividade e de seu coletivo, sempre que possível. Os exercícios de pesquisa que os multiplicadores realizaram na escola, mesmo aqueles que envolviam algum tipo de mensuração objetiva, atraíam a atenção dos colegas, que, diante do resultado, em certos casos, passavam a integrar-se à CAP, agindo em conjunto para melhorar as situações de trabalho.

É importante sinalizar ainda que a experimentação que apresentamos resultou na constituição de Comissões de Saúde em algumas escolas públicas, que vêm elaborando mapas de risco e realizando um monitoramento sistemático dos problemas de saúde dos trabalhadores (com vistas a um Observatório). Enfim, uma série de eventos promotores de saúde foram sendo e continuam a ser produzidos, tendo como ponto de partida um olhar à lupa sobre as situações singulares de trabalho e a experiência dos protagonistas da atividade. Talvez nem seja possível inventariar tudo que vem acontecendo, pois, como temos constatado, este tipo de abordagem metodológica propicia o desencadeamento de vários movimentos em direção à saúde, dado que, nesta dinâmica, os trabalhadores potencializam sua capacidade normativa, (re)criando novas normas de vida (Canguilhem, 1995).

\section{Considerações finais}

A "Promoção da Saúde a partir das Situações de Trabalho" (PSST) pode ser entendida como o processo continuado de compreensão/apreensão, por parte de trabalhadores e pesquisadores profissionais, do real das situações de trabalho, em sua relação com a saúde-doença, com o fim de - a partir dos locais de trabalho - monitorar a organização e as condições de trabalho para atuar preventiva e propositivamente nas fontes potencialmente causadoras de danos à saúde, afirmando e validando as formas de luta eventualmente já em curso.

O caminho que estamos apontando aqui, em grande parte, já é conhecido. O que propomos é um pequeno deslocamento, indicando uma nova referência na compreensão e transformação das situações de trabalho, que é a incorporação estratégica e fundamental dos saberes gerados na atividade. Isso significa considerar o trabalho em sua complexidade, em seu caráter sempre enigmático, sem reduzilo e sem fragmentá-lo, considerando-o especialmente como uma atividade situada, com atores cujos modos de trabalhar são sempre, em alguma medida, singulares; com adversidades, frequentemente pesadas, mas também como um espaço de possíveis sempre negociáveis (Schwartz, 2007).

Acreditamos que a ideia aqui apresentada é pertinente, primeiramente porque contribui para a apreensão dos determinantes múltiplos da saúde, não enfocando somente a doença, nem unicamente os riscos clássicos do trabalho. Por outro lado, porque tem uma perspectiva de continuidade (não é estanque) e porque engendra uma participação direta e efetiva dos trabalhadores, seu comprometimento, condição necessária para compreender-transformar positivamente as situações de trabalho (e a vida). O fato de ter como referência a atividade também nos parece importante, seja porque cada realidade é singular, seja porque as ações implementadas geram novos conhecimentos que podem (re)orientar, em novas bases, as reivindicações do movimento dos trabalhadores em termos de políticas públicas. 


\section{Colaboradores}

Os autores Edil Ferreira da Silva, Jussara Brito, Mary Yale Neves e Milton Athayde participaram, igualmente, de todas as etapas de elaboração do artigo.

\section{Referências}

ATHAYDE, M. Processo produtivo, espaço educativo: um campo de lutas. 1988. Dissertação (Mestrado) - Universidade Federal da Paraíba, João Pessoa. 1988.

ATHAYDE, M. et al. (Orgs.). Trabalhar na escola? "Só inventando o prazer". Rio de Janeiro: Edições Ipub/Cuca/UFRJ, 2001.

BAKHTIN, M. Estética da criação verbal. 4.ed. São Paulo: Martins Fontes, 2003.

BARROS, R.B. Grupo: a afirmação de um simulacro. Porto Alegre: Sulina, 2007.

BRITO, J. Trabalho e saúde nas indústrias de processos químicos: a experiência das trabalhadoras. Rio de Janeiro: Ensp/Fiocruz, 1996.

BRITO, J.; ATHAYDE, M. Trabalho, educação e saúde: o ponto de vista enigmático da atividade. Trab. Educ. Saude, v.1, n.2, p.63-89, 2003.

BRITO, J.; ATHAYDE, M.; NEVES, M.Y. (Orgs.). Caderno de método e procedimentos. Programa de Formação em Saúde, Gênero e Trabalho nas Escolas. João Pessoa: Ed. Universitária UFPB, 2003a.

Caderno de textos. Programa de Formação em Saúde, Gênero e Trabalho nas Escolas. João Pessoa: Ed. Universitária UFPB, 2003b.

Saúde e trabalho na escola. Rio de Janeiro: Cesteh/Ensp/Fiocruz, 1998.

CANGUILHEM, G. O normal e o patológico. Rio de Janeiro: Forense Universitária, 1995.

CLOT, Y. Travail et pouvoir d'agir. Paris: PUF, 2008.

A função psicológica do trabalho. Petrópolis: Vozes, 2006. $\overline{12,2004}$ Le travail entre fonctionnement et développement. Bull. Psychol., v.57, n.1, p.5-

CLOT, Y.; FAÏTA, D. Genre et style en analyse du travail, concepts et méthodes. Travailler, n.4, p.7-42, 2000.

COSTA. J.D. O “Programa de Formação em Saúde, Gênero e Trabalho em Escolas Públicas" e a produção de subjetividades. 2004. Dissertação (Mestrado) - Programa de Pós-graduação em Psicologia Social, Universidade Federal da Paraíba, João Pessoa. 2004.

DANIELLOU, F. (Org.). A ergonomia em busca de seus princípios: debates epistemológicos. São Paulo: Edgard Blücher, 2004.

DEJOURS, C. Da psicopatologia à psicodinâmica do trabalho. In: LANCMAN, S.; SZNELWAR, L.I. (Orgs.). Christophe Dejours: da psicopatologia à psicodinâmica do trabalho. Rio de Janeiro: Fiocruz, 2004. p.47-104.

O fator humano. Rio de Janeiro: Fundação Getúlio Vargas, 1997.

FAÏTA, D. Análise dialógica da atividade profissional. Rio de Janeiro: Imprinta, 2005.

FRANÇA, M.B. Uma comunidade dialógica de pesquisa: atividade e discurso em guichê hospitalar. São Paulo: Edição Fapesp/Educ, 2007.

FREIRE, P. Educação e mudança. 15.ed. Rio de Janeiro: Paz e Terra, 1989.

Pedagogia do oprimido. Rio de Janeiro: Paz e Terra, 1983. 
FREIRE, P. Educação como prática da liberdade. Rio de Janeiro: 1967.

FREIRE, P.; FAÚNDES, A. Por uma pedagogia da pergunta. Rio de Janeiro: Paz e Terra, 1985.

GUÉRIN, F. et al. Compreender o trabalho para transformá-lo: a prática da ergonomia. São Paulo: Edgard Blucher, 2001.

HIRATA, H. Nova divisão sexual do trabalho? Um olhar voltado para a empresa e a sociedade. São Paulo: Boitempo, 2002.

10, 1993

Paradigmes du travail, un "point de vue transversal". Fut. Antérieur, n.16, p.5-

KERGOAT, D. A relação social de sexo: a reprodução das relações sociais à sua subversão. Pro-posições, v.13, n.1, p.47-59, 2002.

. Relações sociais de sexo e divisão sexual do trabalho. In: LOPES, M.; MEYER, D.; WALDOW, V. (Orgs.). Gênero e saúde. Porto Alegre: Artes Médicas, 1996. p.19-28.

Em defesa de uma sociologia das relações sociais: da análise crítica das categorias dominantes à elaboração de uma nova conceituação In: KARTCHEVSKY, A. et al. (Orgs.). O sexo do trabalho. Rio de Janeiro: Paz e Terra, 1986. p.77-93.

LACOMBLEZ, M. L'analyse ergonomique du travail et la formation professionelle. Educ. Permanente, n.124, p.81-8, 1995.

NEVES, M.Y. Trabalho docente e saúde mental: a dor e delícia de ser (tornar-se) professora. 1999. Tese (Doutorado) - Instituto de Psiquiatria, Universidade Federal do Rio de Janeiro, Rio de Janeiro. 1999.

NUNES, B. O sentido do trabalho para merendeiras e serventes em situação de readaptação nas escolas públicas do Rio de Janeiro. 2000. Dissertação (Mestrado) Escola Nacional de Saúde Pública, Fundação Osvaldo Cruz, Rio de Janeiro. 2000.

ODDONE, I. et al. Ambiente de trabalho: a luta dos trabalhadores pela saúde. São Paulo: Hucitec, 1986.

ODDONE, I.; RE, A.; BRIANTE, G. Redécouvrir l'expérience ouvrière: vers une autre psychologie du travail? Paris: Messidor/Editions Sociales, 1981.

OMBREDANE, A.; FAVERGE, J.-M. L'analyse du travail. Paris: PUF, 1955.

ORGANIZAÇÃO PANAMERICANA DE SAÚDE - OPAS. Estrategia de promocion de la salud en Iso lugares de trabajo de America Latina y el Caribe. In: ESTRATÉGIA PARA EL FORTALECIMIENTO DE LA PROMOCIÓN DE LA SALUD EN LOS LUGARES DE TRABAJO EN AMÉRICA LATINA Y EL CARIBE, Anexo 6, San José, Costa Rica, 2000. Disponível em: <http://www.bvsde.paho.org/bvsast/e/fulltext/promocion/promocion.pdf >. Acesso em: 4 out. 2008.

RABARDEL, P. et al. Ergonomie, concepts et méthodes. 5. ed. Toulouse: Octarès, 2007.

SCHWARTZ, Y. Le paradigme ergologique ou um métier de Philosophe. Toulouse: Octarès, 2000a.

A comunidade científica ampliada e o regime de produção de saberes. Trab. Educ., n.7, p.38-46, 2000b.

SCHWARTZ Y.; DURRIVE, L. Trabalho \& ergologia: conversas sobre a atividade humana. Niterói: Ed. UFF, 2007.

SILVA, E.F. Trabalhadores/as de escola e construção de uma "Comunidade Ampliada de Pesquisa": a busca da promoção da saúde a partir dos locais de trabalho. 2003. Tese (Doutorado) - Escola Nacional de Saúde Pública, Fundação Oswaldo Cruz, Rio de Janeiro. 2003. 
SOUZA, K.B. Saúde do trabalhador e práxis educativa. 2000. Dissertação (Mestrado) Núcleo de Tecnologia Educacional em Ciências da Saúde, Universidade Federal do Rio de Janeiro, Rio de Janeiro. 2000.

SURATEAU, A. Normes individuelles, normes sociales dans les définitions de la santé. In: LE BLANC, G. (Org.). Lectures de Canguilhem: le normal et le pathologique. Lyon: ENS Éditions, 2000. p.123-36.

TEIGER, C.; LAVILLE, A. L'aprentissage de l'analyse ergonomique du travail, outil d'une formation pour l'action. Travail et Emploi, n.47, p.53-62, 1991.

VICENTI, A. Ivar Oddone, intelectual orgânico e pesquisador heterodoxo. Les territoires du travail, n.3, p.33-42, 1999.

VIGOTSKI, L. O significado histórico da crise em Psicologia. Uma investigação metodológica. In: Fontes, 1999a. p.203-417.

A consciência como problema da Psicologia do comportamento. In: Teoria e método em Psicologia. 2.ed. São Paulo: Martins Fontes, 1999b. p.55-85.

WISNER, A. A inteligência no trabalho. São Paulo: Fundacentro, 1994.

SILVA, E.F. et al. La promoción de la Salud a artir de las situaciones de trabajo: consideraciones referenciadas en una experiencia con trabajadores de escuelas públicas. Interface - Comunic., Saude, Educ., v.13, n.30, p.107-19, jul./set. 2009.

El objeto de este artículo es el de presentar y discutir lo que denominamos Promoción de la Salud a partir de las Situaciones de Trabajo (PSST). Para tal hacemos uso de una experiencia desarrollada en el estado de Rio de Jlaneiro $Y$ en el municipio de Joao Pessoa, estado de Paraiba, ambos en Brasil: el Programa de Formación en Salud, Género y Trabajo en las Escuelas Públicas. La experimentación ha tenido como punto de partida y de llegada las situaciones concretas de trabajo e involucró, en una perspectiva ergológica, el diálogo sinérgico entre los polos de la experiencia y de los conceptos mediado por el polo ético-epistémico, por la constitución de Comunidades Ampliadas de Pesquisa (CAP). Su realización propició (y sigue propiciando) la producción de varios eventos promotores de salud, englobando modificaciones concretas en la organización y en el ambiente de trabajo, cambios en las formas de lucha por la salud e inoluso transformaciones en el modo de ver el trabajo Y la vida.

Palabras clave: Promoción de la salud. Trabajo. Escuela pública. Salud del trabajador. Ergología. 